\title{
Economic incentive in community nursing: attraction, rejection or indifference? Mireille Kingma*
}

\author{
Address: Nursing and Health Policy, International Council of Nurses, Geneva, Switzerland \\ Email: Mireille Kingma* - kingma@icn.ch \\ * Corresponding author
}

This article is available from: http://www.human-resources-health.com/content///I/2

(C) 2003 Kingma; licensee BioMed Central Ltd. This is an Open Access article: verbatim copying and redistribution of this article are permitted in all media for any purpose, provided this notice is preserved along with the article's original URL.

\begin{abstract}
Background: It is hard to imagine any period in time when economic issues were more visible in health sector decision-making. The search for measures that maximize available resources has never been greater than within the present decade. A staff payroll represents $60 \%-70 \%$ of budgeted health service funds. The cost-effective use of human resources is thus an objective of paramount importance.

Using incentives and disincentives to direct individuals' energies and behaviour is common practice in all work settings, of which the health care system is no exception. The range and influence of economic incentives/disincentives affecting community nurses are the subject of this discussion paper. The tendency by nurses to disregard, and in many cases, deny a direct impact of economic incentives/disincentives on their motivation and professional conduct is of particular interest. The goal of recent research was to determine if economic incentives/disincentives in community nursing exist, whether they have a perceivable impact and in what areas.
\end{abstract}

Conclusion: Understanding the value system of community nurses and how they respond to economic incentives/disincentives facilitates the development of reward systems more likely to be relevant and strategic. If nurse rewards are to become more effective organizational tools, the data suggest that future initiatives should:

- Improve nurses' salary/income relativities (e.g. comparable pay/rates);

- Provide just compensation for job-related expenses (e.g. petrol, clothing);

- Introduce promotional opportunities within the clinical area, rewarding skill and competence development;

- Make available a range of financed rewards.

- Direct (e.g. subsidized education, additional leave, insurance benefits);

- Indirect (e.g. better working conditions, access to professional support network, greater participation in decision-making bodies).

\section{Background}

The half-life of knowledge in the medical fields is estimat- ed to be between five and seven years $[1,2]$. Providers who do not conscientiously pursue a programme to maintain 
state-of-the-art practice could lose half of their competence in that period of time. This implies that the information base upon which clinical judgements are made is in constant flux. Similarly, it suggests that health care policy and interventions must regularly change or adapt in order to keep up with the pace of scientific advances. Change and reform in the health sector tend to be imperative and also the norm.

The health care needs of a given population change over time, responding to demographic, economic, social, technological and environmental trends as well as access to health services, including health education $[3,4]$. The extent to which these needs generate a response may often be a political decision but also reflects the personal motivation of the stakeholders concerned [5].

"The majority of health care interventions in use today are not proven in terms of efficacy and cost effectiveness. It has been argued that $10 \%$ of health care expenditure damages patients' health, $10 \%$ has no effect on their health and $80 \%$ improves population health. The problem is that no-one knows which therapies lie in the 10 and $80 \%$ categories!" [6]. The resulting relative vacuum in terms of demonstrated effectiveness allows for a significant liberty of action in the health sector, especially among highly autonomous professionals.

There is evidence that considerations other than the professional credibility and legitimacy of a given practice are at play. These may include a wide range of factors such as clinical experience, financial incentive, access to equipment, risk taking tolerance and other personal preferences [7]. If health care practices are not selected in terms of efficacy and cost-effectiveness, what is the basis for decision-making?

Individuals interacting within a social setting are known to be subject to intrinsic and extrinsic motivation, often manipulated or managed to strategically meet societal and/or organizational goals $[8,9]$. The practice of professionals, traditionally granted a high degree of autonomy [10] and working within an environment in constant transition and changing priorities [11], may be particularly sensitive or vulnerable to the introduction of incentives and disincentives, of whatever nature.

There is increasing evidence that the clinical judgement and professional conduct of physicians are affected by economic incentives and disincentives [12-16]. There is very little information however, with regard to the impact of such measures on nurses [17]. On the contrary, nurses have been known to express little interest in economic incentives/disincentives and disclaim any potential influence of remuneration strategies on their professional conduct [18]. A need to verify this perception stimulated recent research [19].

\section{Methods}

There is a recognized scarcity of information on the subject of economic incentives/disincentives as they relate to nurses in general, and community nurses in particular. Research questions were developed to direct the investigation and three major areas of interest were identified:

- What are the economic incentives/disincentives for community nurses?

- Are community nurses aware of economic incentives/ disincentives?

- What is the impact of economic incentives/disincentives on nurses?

Perceptions of nurses providing direct care, the nursing community in general and non-nurse colleagues were considered of equal importance. A qualitative research methodology for the generation, collection and analysis of valid data was developed and implemented. In order to guarantee a range of different economic policies, including remuneration strategies, community nurses and key informants were interviewed from two research sites (i.e. London and Geneva) and four employment settings that applied five different nurse-payment financing systems: salaried employee in government-financed service; salaried employee in government-financed service but contracted out; salaried employee in government-subsidized not-for-profit organization; independent practitioner; salaried employee in for-profit agency. A total of 95 individuals provided data; the research methods included participant observation, individual interviews and focus groups.

\section{Results and discussion}

The research documented a range of remuneration strategies and their effect on nurses' attitudes and behaviour. The data highlight the presence of two categories of economic measures: a) financial incentives involving a monetary payment (e.g. salary, bonus, fee), and b) financed rewards referring to concessions or privileges that have financial implications for the employer (i.e. cost) but no direct monetary payment to the recipient (e.g. subsidized continuing education, additional leave).

Nurses' attitudes towards and reactions to these economic measures are presented in this paper. The text ends with a discussion of what respondents and key informants felt were significantly valued and socially acceptable economic incentives likely to positively influence the motivation and behaviour of community nurses in the future. 
Table I: Remuneration strategies

\begin{tabular}{cl}
\hline Means & Examples \\
\hline Financial incentives & \\
Monetary reward & Salary \\
Compensation & Merit bonus \\
Financed rewards & Petrol allowance \\
Direct & Uniform allowance \\
Indirect & Subsidized continuing education \\
& Paid sabbatical leave \\
& Access to professional support network \\
& Adequate staff/resources in the workplace \\
\hline
\end{tabular}

Analysis of the data provided the basis for recommendations proposing specific reward strategies to be introduced or reinforced.

The widespread rejection by respondents of an economic frame of reference as relevant in employment decisions, professional development, clinical activity and self-image was noted throughout the research process. The profession's past and present do not encourage nurses to accept a definition of their self worth or self image using financial terms of reference. They are nonetheless sensitive to, and may be influenced by, a certain range of economic incentives/disincentives. This knowledge facilitates the creation and introduction of more admissible and strategically powerful motivating factors in the area of nursing.

Nurses represent the largest category of health workers and provide $80 \%$ of direct patient care $[20,21]$. Their contribution is not limited, however, to the provision of services. Nurses are also effective change agents within the health sector and society as a whole. Improving the management and energy focus of such a significant workforce is possible with suitably targeted economic incentives/disincentives. This would in turn support the implementation of more viable reforms in the future and enable more realistic predictions of their outcomes. The data presented may bring new insights that will strengthen health services planning and management.

\section{Economic incentives}

For the purposes of this paper, an economic incentive is defined as the payment or concession encouraging effort in work. An economic disincentive is the absence of adequate payment or concession, or its withdrawal, thus discouraging action or effort in work. The term economic incentive is used generically to include all staff concessions requiring an investment or allocation of funds.
Financial incentives, are defined as a category of economic incentives, specifically referring to direct monetary payment from employer to employee. The attitudes and behaviour of salaried employees and professional workers are acknowledged to be influenced by financial incentives but also financed rewards (i.e. a concession or privilege that has financial implications for the employer - cost but no direct monetary payment to the recipient). Examples of these various remuneration strategies are given in Table 1.

The relevance and impact of economic incentives/disincentives vary according to the context and personal value systems of those involved. Rewards are used as a means of recruitment and retention of staff $[8,9]$. Economic incentives have also been demonstrated to influence career choices as well as priority setting within an assigned list of duties [7].

Nurses, as a category of workers, have in the past been portrayed as less likely to be influenced or interested in financial gain [5]. Setting aside the traditional image of the nurse as an angel, volunteer or devoted religious sister, modern nurses are still described in the professional press as having an apparent disinterest in monetary rewards:

- "Nursing has never been seen as a financially rewarding career." [22]

- "A majority [of nurses surveyed] (64.5\%) believe nursing to be a vocation." [23]

- "The entire idea of offering incentives casts an image of impropriety upon the nursing profession." [24]

- "The dedicated nurses keeping services going are not doing it for the money." [25]

Several nurses in the study confirmed this attitude: 
Table 2: Nurses' perceptions of incentives and disincentives

Incentive/Disin- Findings
centive

Salary/lncome Salary was not perceived spontaneously as an economic incentive/disincentive and was most often not considered in career moves. Exceptions were identified involving jobs offering similar working conditions (e.g. hours) and changes in civil status (e.g. married to divorced).

In London, comments on salary relativities were restricted to nursing team members. In Geneva, poor relativities in salary/ hourly rates between nurses and other workers were often highlighted.

It was suggested that the poor salary progression within a given pay grade (comparison of starting and retirement salary) may undermine nurses' commitment to their profession as a long-term career.

Clinical grading

Clinical grading (career structure) in London was said to perpetuate promotional opportunities in management as opposed to clinical nursing and failed to reward individual areas of expertise and professional development. The autonomy required in community nursing was, however, recognized in the overall grading resulting in higher pay.

In Geneva, clinical grading recognized the global vision and public health expertise of nurses with post-basic qualifications as well as clinical specialities. Clinical grading did not exist for nurses operating within the fee-for-service/fee-for-time system and the for-profit setting.

Car access Personal cars were required as a condition of employment. With one exception, car pools had been eliminated as a cost-containment measure. Recent subsidized public transport was reported in the two public-funded agencies. Allowances for car maintenance were granted by one employer although claimed inadequate. The purchase of a car was considered a significant personal investment for nurses. Vandalism was also mentioned as a financial disincentive

Petrol A set allowance was provided to compensate for petrol expenses. There was consensus at both research sites that these allowances did not cover the total cost.

Parking Parking fees were paid for the salaried nurses, although parking fines most often were not. Parking discs were provided to General Practitioners (GPs) but not for nurses.

Uniform/laundry Nurses were no longer required to wear uniforms. Aprons were provided to the salaried nurses, while independent nurses could purchase disposable aprons at bulk rate. Several London nurses felt that using personal clothes represented important personal initial purchase and ongoing maintenance costs, as their clothing allowance was considered to be inadequate. This issue was mentioned only twice by Geneva nurses, although no allowances were provided.

Subsidised cafeteria No subsidized cafeterias were available to nurses in either setting. Although meals represented a significant additional cost (in comparison with a hospital setting), this was not spontaneously mentioned by interviewees.

Unsocial hours Shift differentials (i.e. extra pay for working nights and weekends) were considered to be insignificant and not a motivating factor in the workplace. There is, however, an indirect economic advantage for community nurses working more regular hours with regard to better access and lower fees for child care (mentioned only once).

Overtime Overtime was compensated by time in lieu for salaried nurses and in general did not constitute a major issue. Although not strictly overtime, the time spent by independent nurses on indirect care (i.e. liaison duties) was not recognized by the reimbursement system and considered a major financial burden as well as concern.

Pension

Cost-of-living

One London respondent mentioned improved pension rights, while another claimed lower benefits. Several salaried Geneva nurses noted equal benefits for private and public-sector nurses. Independent nurses were obliged to contribute to the government basic pension scheme.

London nurses were entitled to cost-of-living increases. The budget freeze applied in Geneva eliminated these automatic allowances for salaried nurses. Independent nurses were tariff-dependent and these were not linked to a cost-of-living scale. Nurses working for the Swiss for-profit agency did not benefit from cost-of-living increases.

Geographic-specific London nurses benefited from Inner and Outer London Weighting allowances. Such allowances did not exist in the Geneva allowances setting.

Bonuses

Nurses working at the for-profit agency were entitled to productivity and merit bonuses, although the criteria applied were unknown. Salaried (non-profit employer) nurses were eligible for "loyalty" bonuses after 5 years of service. London nurse managers received performance-related pay, merit and productivity bonuses, although community nurses did not.

Miscellaneous cash disbursements In addition to the above financial incentives, Geneva salaried (non-profit employer) nurses were granted child support supplements, partial payment of health insurance premiums and an allowance for the purchase of a diary. These incentives were not mentioned by nurses from other workplaces.

Staff coverage The London facility was reported to experience chronic staff shortages, high turnover and high absenteeism. In both settings, access to temporary nurses was felt to depend on the Area Manager's personal priorities.

Access to supplies and equipment Job contracts Access to supplies, while considered adequate, was perceived to be more difficult than previously. As a cost-containment measure, stocks had been reduced and orders needed to be justified with greater rigour.

Although short-term contracts were widely introduced during a certain period as a cost-containment measure, this was no longer the practice. The number of part-time jobs was also being reduced. Many of the London nurses were contracted out to GP fundholders, their duties largely being determined by contract negotiation.

Access to continuing All employers were perceived to support continuing education and a lifelong learning approach.

education

Access to professional The elimination of Team Leaders was experienced by London nurses as a loss of professional support, while the development support of the nurse manager hierarchy and the introduction of Clinical Specialists were seen to increase the professional support available to Geneva nurses. Respondents, however, were aware of the risk of professional isolation due to the working conditions specific to community nursing. 
- "If they were interested in money, they wouldn't be here."

• "I don't do it for the money... I don't want money."

- "Nurses didn't come into the profession to focus on pay."

- "Nurses are not interested in financial reward - they are basically committed professionals."

• "Nurses don't think in terms of financial incentives."

Nurses' awareness of economic incentives and disincentives in the health sector and how these are perceived are fundamental areas of interest. A summary of the collected data is presented in the following section.

\section{Economic incentives and disincentives}

Among economic incentives and disincentives, direct monetary rewards or compensation are the most visible. Although financial incentives/disincentives were in general not mentioned spontaneously, questioning did reveal a range of payments and allocations targeting nurses. Financed rewards (direct and indirect) proved to be very relevant to community nurses and are included in the analysis. Table 2 recapitulates findings in this area. While the list is not exhaustive, it reflects the discussions held with respondents and key informants. Nurses working in other countries/settings may benefit from different specific incentives (e.g. housing allowance). The proposed classification of incentives (see above) should however remain relevant.

Contrary to the widespread initial denial by nurses that economic incentives exist, the findings highlighted a wide range of measures. Equally significant however were the nurses' responses to these incentives once they were identified and discussed in more detail.

\section{Nurses' perceptions/responses}

In general, nurses tended to have four reactions. They viewed economic incentives/disincentives with indifference, positively, negatively or with ambiguity.

\section{Indifference}

When asked to name the economic incentives in community nursing, almost without exception London interviewees spontaneously responded that there were none. While consistently not perceived as such, salary is a major and usually the most important financial incentive/disincentive $[8,26,27]$. The absence of references made to salary is therefore important as is the complete disassociation observed between basic salary and economic incentive. In an extreme case, a respondent claimed she got paid but did not get any financial reward. This supports the theory that salary may be perceived as a condition of work and not an incentive [9].

Specific references made to the higher grade classification of community nurses working in the National Health Service (NHS) recognizing their greater autonomy (as compared to hospital nurses) came more frequently from key informants and/or non-nurses. This may suggest that nurse managers or individuals from other disciplines perceive salary and economic incentives differently. The fact that basic pay and grade classification were not mentioned by community nurses indicates a certain indifference or lack of awareness on their part. The data tended to support the first option.

Two nurses recognized that private sector hospitals paid higher salaries and that NHS employment had meant a decrease in salary (a financial disincentive of approximately $€ 300 /$ month or $30 \%$ of a starting salary). Certain nurses having moved within the NHS reported a lower income in the community as compared with the hospital and community midwifery. This decrease in revenue was not only accepted in the career moves made but was not spontaneously referred to in the interviews. Its absence again indicates a degree of indifference on the part of nurses.

While there was agreement among the private salaried (non-profit employer) nurses that there was no economic incentive to enter community nursing, there was repeated reference to the similar job classification and salary with nurses in the public sector hospital. As in London, the association of financial incentive with income in addition to salary (as opposed to the salary itself) was made.

Geneva nurses repeatedly claimed a disinterest in financial aspects of their work claiming that salary was not a priority or part of employment decision-making. They claimed to be often unaware of salary and benefits before receiving their first pay check. Many were unable to give information on their past or present pay details.

With questioning, there was acknowledgement that the loss of shift differentials (e.g. night duty) when transferred to the community did represent a reduction in income. This however was said to be insignificant and not noticeable. In London, key informants reported that the higher grade classification of community nurses compensated for the loss of income from a reduced number of shift differentials. This could explain the apparent lack of interest in paycheque composition but not the disregard when considering career moves. 
Nurses in both settings continued to work weekends and benefit from supplementary payments. London respondents tended not to give value judgements with regard to weekend differentials while in Geneva, nurses were quite explicit that the extra pay was not considered a motivating factor. It can be argued that nurses anxious to benefit from the supplementary income provided by shift differentials would not enter community nursing and therefore would not be among the respondents. No indication from the key informants however suggested that shift differentials were a significant motivating factor among nurses in any setting.

Reported claims for overtime in both settings appeared to be minimal (except for the Geneva for-profit agency) while the incidence of working overtime varied greatly according to the interviewees. It was said that the infrastructure in hospitals was better and therefore more likely to facilitate the claim process. Community nurses tended to take time unofficially when the team workload permitted. In most cases, overtime was linked with working through lunch breaks and often accepted as part of the daily routine in spite of possible harmful health consequences. Overtime payment or compensation was a financial incentive offered but often not claimed.

Nurses working for the Geneva for-profit agency reported no economic incentive working in the community although they had received productivitybonuses the preceding year. In addition, they were entitled to merit increases (as opposed to yearly step increases) but ignored the criteria applied. The productivity and merit bonuses granted were not considered to have a great impact on nurses' activities. Three factors could be significant: a) the recent creation of the agency, b) the high turnover of staff, and c) the lack of nurses' awareness with regard to the bonus criteria.

One employer offered a loyalty bonus for community nurses after 5 years of service. While it was appreciated, it was never reported to be a major recruitment or retention tool.

Applying the classification of economic incentives presented above, community nurses responded to financial incentives (i.e. monetary rewards and compensation) with claimed indifference.

\section{Positive perceptions}

Economic incentives welcomed by nurses and thought to be positive were limited to education-related financed rewards. Nurses reported good access to continuing education. While there was general appreciation for the professional development opportunities provided, the converted Enrolled Nurses (UK) expressed the greatest benefit claiming to have acquired options for the future. Considering the imminent redundancy status of many ENs, this reflects the urgency for higher qualifications to ensure job eligibility.

Many nurses however felt that despite the employer's support, the personal investment in further education was not cost-effective in financial terms but rather a source of professional growth and satisfaction. Even in the case of substantial employer subsidies (e.g. 75\% of salary provided by one employer), these measures were not perceived as financial incentives or a recruitment advantage.

\section{Negative perceptions}

Economic incentives need to be considered within the general remuneration strategy which was felt to be inappropriate and "laughable" by one of the focus groups. This is reflected by the numerous reward measures that are perceived by community nurses as having a negative impact.

Although salary was reported to be unimportant (see above), relative salary generated a much more emotional reaction. Geneva nurses repeatedly associated their poor relative pay with a low societal value given to nursing outcomes in general and human well-being in particular. Unfavourable relativities were interpreted as insulting and an injustice. This would suggest that nurses were more sensitive to the social implications of salary/income than the financial gain.

- "I am always insulted that my hourly tariff compares so badly with other workers."

- "The difference of [payment] with aides is not normal. Either nurses are not well enough paid or aides are too well paid. The difference doesn't justify our education, responsibilities, consequences of care."

- "The hourly increased rate is a small, slight progress. If compared with the washing machine repairman who bills CHF 100/hour [as opposed to CHF 64/hour for nurses], this somehow reflects strange values for the human being."

Resentment also was expressed by the independent nurses that much of their work was not recognized and therefore not remunerated. While some nurses felt exploited and obliged to subsidize health care, others accepted a voluntary participation in the health services provided. Many however coped with the situation by manipulating the system thereby creating some ethical dilemmas and/or introducing cynical practices in health care. 
- "...can get tired of doing volunteer work. Talking 45 minutes with a patient about her anxiety knowing that the nurse won't be paid gets to be a bit much."

- "We are only paid for what is done in the field by the patient. All the time spent elsewhere is on us. We give our time free of charge, subsidizing the health system."

- "Before we did 'arrange' invoices claiming partial baths with technical care... This was known and accepted as a practice although the insurance companies didn't know."

All compensation payments were reported to be inadequate, in other words not covering the costs incurred by the community nurses. The resentment was reinforced by the mandatory nature of the expenses. For example, car transport was required for carrying out assigned duties but the reimbursement received was said to be insufficient. Petrol allowances were felt to be at best a reimbursement but more frequently a partial payment. These expenses were considered a financial disincentive. Feelings of exploitation were also expressed.

Parking represents not only a financial cost but also a stressful element in the daily life of community nurses. One nurse felt that parking difficulties could be a reason to quit practice. The irony of a public employee fining another public employee was not lost to one of the NHS nurses. Parking fines were considered to be a definite financial disincentive in community nursing. Furthermore, there was ill feeling with regard to the different treatment reserved for GPs and community nurses visiting the same patients (i.e. access to parking discs). Again the social implications and value judgements were taken seriously by the respondents.

Several cases were reported in the press which generated great protest and indignation. For example, a nurse providing extended care to a dying patient and his family had her car clamped and towed although properly identified as being on official public health business. There was great protest when it was learned that the nurse had to leave her wedding ring on deposit to claim back her car [28]; or another case, where a nurse picking up urgent medications for her patient was delayed for one hour until her car was liberated having been clamped in front of the pharmacy.

The elimination of uniforms was considered a positive initiative by many nurses who felt safer making home visits in street clothes. Not being identified as a possible source of drugs and/or syringes or as part of the establishment may in certain neighbourhoods be judged a safety measure for staff. Considering the inadequate clothes allowance provided staff however, this must also be seen as a cost-saving measure of the employer. The personal cost of purchasing clothes suitable for professional practice and their maintenance was reported to be a significant expense by most nurses and therefore a financial disincentive. Cleaning costs of street clothes were also higher than the laundering of uniforms. Highlighted in this example is the association of an insufficient reimbursement or compensation with the concept of a pejorative value judgement of the employer. Nurses concluded that the payment was in fact an insult as well as a financial disincentive. The tone and content of the interviews suggest that the value judgement was considered more significant.

Although not specifically mentioned, the shift in cost burden from the employer to the employee forced staff to subsidize the services provided. While it may be argued that many workers do not get a clothes allowance, the important distinction made between hospital and community nurses must in this case be kept in mind.

One of the economic incentives mentioned frequently by the respondents was the employer's investment in guaranteeing adequate staff coverage. Critical staff shortages were reported in London while this did not appear to be the case in Geneva. Responses recorded included low morale, feelings of resentment and exploitation as well as frustration.

In both settings, cost-containment measures with regard to supplies and equipment were felt to decrease the ease of access and often increase the nurses' workload (e.g. bureaucratic forms, personal responsibility for the delivery of supplies).

Especially in London, the content, lifespan and negotiation process of job contracts were reported to affect staff's job security, job description, job location, priority setting, accountability and professional development. Responses included demotivation, job insecurity, reduced job satisfaction and resentment. In both settings however, shortterm contracts were once again being replaced by longer term contracts thus improving staff's job security and motivation.

Research has demonstrated that a supportive manager may reduce the negative effects of a less than desirable environment [29] while the lack of manager support is perceived as a source of great stress [30]. The risk of professional isolation was felt keenly by nurses in both settings. It was more evident in London as nurses were still dealing with the recent elimination of Team Leaders. The great sense of abandonment expressed by the nurses would indicate that access to professional support is a fundamental investment employers must consider. 
The existence of bonuses was most relevant in the context where the target population was management as opposed to community nurses. Nurses, however, were confronted with the reality that these bonuses were based on their productivity while the benefits were not shared with them. The level of resentment was observed to increase as the degree of perceived managerial support decreased.

Furthermore, the climate of suspicion created by these bonuses and the perceived lack of information concerning them is of interest for future personnel managers and policy makers. Key informants confirmed that management incentives can at times be seen as staff disincentives.

The concept of nurses doing the best they can ran through many of the interviews. The possibility of doing better than "best" if given an economic incentive may be unacceptable to nurses and one of the issues that needs to be explored.

The perceptions of nurse managers are also of value. While some felt the incentives produced stress rather than creativity, others believed the rewards misdirected, channelling savings/benefits to the greater organization rather than reinvesting in the responsible unit. The notion of nurses "doing their best" was echoed in the statement of nurse managers although conceding that incentives had had an impact on the direction of their efforts.

- "There are incentives for managers. They help keep me on track. Not a motivating factor. I am doing the best I can, but I appreciate the reward once the review period comes to a close."

- "I came to the job with the attitude I would always try to do the best possible. In fact, incentives make you focus on the employer's and manager's interests. It does work [but] I don't like the idea that I could do better than best."

More than half of the reward strategies identified in the study are perceived to have a negative impact on community nurses. Of the four types of economic incentives, only the direct financed reward is absent from this category.

\section{Ambiguous reactions}

Several of the reward strategies generated ambiguous reactions. Nurses were not yet sure of the nature of the overall impact or there was no consensus among the respondents. There were surprisingly few however. This suggests that although nurses are often reluctant to accept the existence of economic incentives/disincentives linked to community nursing, their views on most of the related issues are definite once the discussion is opened.
While only relevant for London nurses, many respondents had no knowledge of differences in the allocation of areaspecific allowances within the Trust (Inner/Outer London weighting). One respondent aware of the financial incentive claimed it had no impact on his career move decision. This was felt to be the case for community nurses in general although contradicted by another source who felt that nurses transfer worksite in order to benefit from the allowance.

On the basis of this conflicting information, it is difficult to conclude that geographic allowances motivate or affect career choices. Analysis is further complicated as the allowance size differs according to grade and step and may therefore represent a bigger or smaller factor among other considerations. The lack of knowledge on the part of nurses as to the potential impact is significant. More research is needed to determine general tendencies.

A fee-for-service payment system tends to encourage induced demand and/or patient selection (i.e. generating unnecessary work for personal economic gain and/or choosing patients that will provide the greatest economic advantage for the care provider). The potential financial interest for independent nurses to select patients requiring higher as opposed to lower paid interventions existed under the past Geneva reimbursement mechanism. While interviewees acknowledged this possibility and a few cases were identified, the occurrence was said to be negligible and eliminated by peer review and pressure. The frequent references to not wishing to abuse the system implies an awareness of potential financial incentives in fee-for-service and fee-for-time reimbursements.

In Geneva, the adequacy of the salary differences between clinical grades was questioned. There was doubt that this financial reward could be considered an incentive for professional advancement. Once again, however, an improved social image of the nurse was associated directly with an increase in grade/salary.

\section{Summary}

Table 3 represents an overview of the economic measures applied and the nurses' responses. The relative relevance and acceptability of the four types of reward mechanisms identified is significant for future planning.

By far, the responses generated by economic incentives tend to be indifference or negative. Only financed rewards, both direct and indirect, were perceived to be clearly positive. Financial incentives were never recognized as being positive and at best were received with ambiguous reactions. Indifference however clearly dominated the recorded perceptions of monetary rewards. 
Table 3: Nurses' responses to economic measures

\begin{tabular}{|c|c|c|c|c|}
\hline Economic Incentive/Disincentive & Indifference & Positive & Negative & Ambiguous \\
\hline \multicolumn{5}{|l|}{ Monetary reward } \\
\hline Salary & $\mathbf{C H}+\mathbf{U K}$ & & & \\
\hline Relative salary & & & $\mathbf{C H}+\mathbf{U K}$ & \\
\hline Grade classification & $\mathbf{C H}+\mathbf{U K}$ & & & \\
\hline \multicolumn{5}{|l|}{ Clinical grades } \\
\hline Shift differentials & $\mathbf{C H}+\mathbf{U K}$ & & & $\mathbf{C H}$ \\
\hline Overtime & $\mathbf{C H}+\mathbf{U K}$ & & & \\
\hline Nurse bonuses & $\mathbf{C H}+\mathbf{U K}$ & & & \\
\hline Management bonuses & & & $\mathbf{C H}+\mathbf{U K}$ & \\
\hline Induced demand & & & & $\mathbf{C H}+\mathbf{U K}$ \\
\hline Area-specific bonuses & & & & $\mathbf{C H}+\mathbf{U K}$ \\
\hline \multicolumn{5}{|l|}{ Compensation } \\
\hline Car & & & $\mathbf{C H}+\mathbf{U K}$ & \\
\hline Petrol & & & $\mathbf{C H}+\mathbf{U K}$ & \\
\hline Parking & & & $\mathbf{C H}+\mathbf{U K}$ & \\
\hline Uniform & & & $\mathbf{C H}+\mathbf{U K}$ & \\
\hline \multicolumn{5}{|l|}{ Financed reward: Direct } \\
\hline Subsidized sabbatical/study leave & & $\mathbf{C H}+\mathbf{U K}$ & & \\
\hline Tuition & & $\mathrm{CH}+\mathrm{UK}$ & & \\
\hline \multicolumn{5}{|l|}{ Financed reward: Indirect } \\
\hline Staff coverage & & $\mathbf{C H}$ & UK & \\
\hline Job contracts (short term) & & & $\mathbf{C H}+\mathbf{U K}$ & \\
\hline Professional support & & $\mathbf{C H}$ & UK & \\
\hline
\end{tabular}

$\mathrm{UK}=$ London nurses, $\mathrm{CH}=$ Geneva nurses, $\mathrm{CH}+\mathrm{UK}=$ London and Geneva nurses

A wide range of economic incentives/disincentives were identified by nurses once the subject was opened with gentle questioning. After review of the data, the impression given is that nurses tend not to express themselves in financial terms and are often reluctant to admit that monetary reward is of any significance. The insistence of Geneva nurses in linking economic reward with societal value judgements and relative social image suggests the emotional role played by financial incentives in the development of personal and professional identity. The frequency with which nurses felt they were being devalued by the inadequacy of the existing economic incentives may have resulted in a rejection of defining themselves or their work in terms of money. It may be true that "altruism and service become a form of self-coercion that makes economic inequality and asymmetry appear normal, natural and desirable as the badge of professional status" (Turkoski, quoted in [31]).

Professional pride in the image of nurses doing the very best possible job may make it impossible to accept the concept of working harder for financial gain. The distinction between "token of appreciation" and "motivating factor" may need to be explored with nurses in a future study.
Knowledge of nurses' reactions to economic incentives and disincentives facilitates the creation of positive measures that will encourage desired behaviours. Looking toward the future, interviewees were asked to identify economic incentives that would be relevant and likely to influence their behaviour in the workplace. The next section presents an overview of their ideas.

\section{Suggested incentives}

Possible economic incentives relevant to nurses and likely to influence behaviour were explored with interviewees in both research settings. There was agreement that incentives must come from within the nurses' value systems. Financial incentives, as a category of economic incentives, were mentioned most frequently although investments in improving working conditions and rewards in kind were suggested as more meaningful for nurses. As a general principle, key informants agreed that direct and indirect economic incentives should exist at comparable levels with other professions.

In the light of the indifference nurses showed to monetary payments in the interviews, the number of suggestions related to financial incentives is surprising. The attention paid to salary increases was greater than to the salary itself. This suggests that the relative increase may be significant rather than the absolute sum of money. While nurses re- 
ferred often to their poor salary relativities (among nursing personnel and/or other occupations), comparable pay was never mentioned as a goal for the future.

One source felt incentives were helpful in addressing poor performance as opposed to motivating excellence. Withholding incentives was seen as a clear way of indicating to individuals the need for change. There did not appear to be consensus however on how nurses perceived financial reward as a motivating mechanism.

\section{Performance-related pay}

Performance-related pay had been introduced in many sectors of both countries, including the public sector. This economic incentive generated strong reactions from the interviewees, leaving no one indifferent. London nurses having had more experience with performance-related pay, through management bonuses, considered the possibility in greater detail. In general, performance-related pay was believed to be inappropriate for nurses and great concern was voiced as to the criteria used for determining success. Nurses continued to claim that their interventions could not easily be measured in a relevant manner (quality vs. quantity) although standards of practice had been developed and were applied during clinical audit. The potential negative impact of performance-related pay on interpersonal relationships within the nursing and health teams (e.g. competition) as well as with the patient was also feared.

At both research sites, interest was expressed in introducing reverse merit awards or penalties associated with a yearly evaluation process. Another variation of performance-related pay provided merit increases for team productivity. The point was made however that once the amount was divided among the team members, the resulting reward may be quite small ("peanuts") and not a sufficient financial incentive.

\section{Economic incentives}

Besides an increase in basic salary already mentioned above, the following suggestions were made:

- Improved work environment, e.g. free tea and coffee, mobile phones

- Educational programmes better focused on nurses' interests

- Private health insurance or added health benefits

- Social events to improve team spirit

- Rewards in kind, e.g. airline ticket, no taxes
- Choice of incentive, e.g. extra pay vs. extra vacation.

While there was no consensus as to the relevance and power of financial rewards, nurses in general agreed that performance-related pay was inappropriate for nursing care within a social service. It is not difficult to understand that nurses would be against the introduction of performance-related pay considering their history. Given their position within a social or caring sector, there are common arguments with practitioners from similar disciplines (e.g. quality vs. quantity indicators, short vs. long time frame, support vs. product) [32,33]. Nurses were confronted with the difficulty of predicting the outcomes of nursing interventions within a given period of time determined by fiscal considerations. In addition, nurses have been unable to define and clearly articulate what they do thus hampering the identification of relevant performance indicators. They have consistently been paid unjustly for their interventions thereby generating distrust of any payment mechanism. The validity of team (as opposed to individual) incentives while more acceptable in theory was questioned because of their probable small size.

Having set no limits on the creation of future incentives, the modesty of the suggestions was a surprise. In view of the serious financial disincentives previously mentioned, the recommendation to improve working conditions by providing tea and coffee free of charge could appear to be disproportionate. This may be linked with nurses' self image and frequently noted lack of assertiveness [34]. It also supports the suggestion that rewards in kind may be more appropriate for nurses or perceived to be more acceptable than monetary incentives.

\section{Conclusions}

In summary, economic incentives and disincentives exist in community nursing. Their relevance and impact vary according to the context and personal value systems of those involved. The nurses' disassociation of salary and economic incentive is significant as are the social implications of relative salaries. Nurses repeatedly claimed that financial factors did not enter the employment decisionmaking process. Compensation payments (e.g. petrol) were consistently reported to be inadequate and linked with unspoken derogatory value judgements (e.g. insulting) applied by the employer and/or society. At the same time, the nurse was often portrayed as an individual subsidizing the health service.

The adequacy of payment determined to a great extent its perception as a financial incentive or disincentive. An incentive perceived as small or insufficient was often considered a disincentive. Furthermore, the size of payment was implied to affect its power as a motivator for action. 
Increases/allowances/payments identified were rarely acknowledged as motivators. The fact that nurse managers recognized that bonuses did alter their priorities and methods of work suggests that nurses may be sensitive to cash payments but that: a) the amounts were not considered sufficiently important in light of other considerations, or b) it was felt unacceptable to admit financial temptations.

Bonuses were considered to influence behaviour and attitudes but only when the reward criteria were clearly known to the recipients. The nurses' acceptance of management bonuses tended to depend on the direct support provided by the managers in question. Economic incentives linked to financing conditions of work were seen to be significant for nurses' daily lives. In general, nurses were sensitive to efforts to facilitate or impede their work.

Nurses tended not to express themselves in financial terms, often reluctant to admit that monetary reward was of any significance. While many nurses recommended a general increase in salary as the most relevant economic incentive, as much importance was given to the relative salary and its impact on social status as to financial gain. Other suggested economic incentives were modest in nature and may reflect certain personal characteristics of individuals attracted to nursing.

This study investigated the impression that community nurses are not affected by economic incentives/disincentives. The data collected tend to refute this prevailing belief. Using incentives and disincentives to direct individuals' energies thus rewarding desired behaviours is common practice in many social interactions (between persons and between groups of persons). This is especially apparent within work settings and the health care system is no exception.

Economic incentives/disincentives exist in the health sector and community nurses are sensitive to their influence. If nurse rewards are to become more effective organizational tools, the data suggest that future initiatives should:

- Improve nurses' salary/income relativities (e.g. comparable pay/rates).

- Provide just compensation for job-related expenses (e.g. petrol, clothing).

- Introduce promotional opportunities within the clinical area rewarding skill/competency development.

- Make available a range of financed rewards (often considered more socially acceptable):
- Direct (e.g. subsidized education, additional leave, insurance benefits);

- Indirect (e.g. better working conditions, access to professional support network, greater participation in decisionmaking bodies).

If performance-related bonuses are to be successfully implemented in a clinical setting, criteria should clearly capture qualitative dimensions of care, indicators should be easily monitored, the rewards must be of a significant nature (e.g. type, monetary value) and the language should reflect the notion of "appreciation" for work well done as opposed to "incentive" or "bonus" calling for extra effort. The widespread resistance to such schemes, increasing evidence of their potential demotivating effect on creative, professional workers, and the difficulty of measuring qualitative outcomes in a service sector are however serious arguments against their introduction.

If we could understand, and could then predict, the ways in which individuals were motivated we could influence them by changing the components of that motivation process. Is that manipulation - or management?

(Handy, 1993, p29-30)

Understanding the value system of community nurses and how they respond to economic incentives/disincentives facilitates the development of reward systems likely to be more relevant and strategic.

\section{Competing interests}

None declared.

\section{Acknowledgements}

I would like to take this opportunity to express appreciation for the ongoing support provided by my $\mathrm{PhD}$ supervisor, Yolande Coombes, and nursing organizations - the International Council of Nurses and the Swiss Nurses Association. I would also like to thank the respondents and key informants who generously gave of their time, sharing with me their life experiences and knowledge. Finally, I would like to thank WHO colleagues who encouraged me to disseminate the findings of my research.

\section{References}

I. Curchod D Libérer l'avenir Soins Infirmiers 84-88 1996 March

2. Joel LA Expanding paradigms of self-care Am J Nurs 1995, 95:7

3. Buchan J and Ball J Caring Costs - Nursing Costs and Benefits: A review for the RCN Brighton: Institute of Manpower Studies I991,

4. Martin J Public debate: Santé publique: un luxe hors de prix? Geneva 1996,

5. Hornby P and Sidney E Motivation and Health Service Performance Geneva: World Health Organization 1988 ,

6. Maynard A Table manners at the health care feast Eurohealth 1996, 2(I):6-7

7. Wennberg Small area analysis and the medical care outcome problem In Research Methodology: Strengthening Causal Interpretations Of Non-experimental Data (Edited by: Sechrest L, Perrin E, Binker J) Rockville, MD: Department of Health and Human Services 1990, I77-206 
8. Armstrong M Employee Reward London: Institute of Personnel and Development 1996,

9. Handy C Understanding Organizations London: Penguin Books 1993,

10. Morgan M, Calnan M and Manning N Sociological Approaches to Health and Medicine London: Croom Helm I985,

II. Ferlie E Large-scale organizational and managerial change in health care: A review of the literature Journal of Health Services Research and Policy 1997, 2(3): 180-189

12. Emanuel $E$ and DublerN N Preserving the physician-patient relationship in the era of managed care JAMA 1995, 273(4):323329

13. Hillman A Financial incentives for physicians in HMOs: Is there a conflict of interest? New England Journal of Medicine 1987, 3 I7(27): 1743-1748

14. Hughes D General practitioners and the new contract: Promoting better health through financial incentives Health Policy 1993, 25:39-50

15. Sulmasy D Physicians, cost control, and ethics Annals of Internal Medicine 1992, I I 6(I I):920-926

16. Woolhandler S and Himmelstein D Extreme risk - The new corporate proposition for physicians New England Journal of Medicine 1995, 333(25): | 706- I707

17. Buchan J Flexibility Or Fragmentation? Trends And Prospects In Nurses Pay London: King's Fund Institute 1992,

18. Diers D On money IMAGE: Journal of Nursing Scholarship 1988, 20(3): 122

19. Kingma M Economic policy: incentive or disincentive for community nurses? PhD thesis London School of Hygiene and Tropical Medicine, University of London 1998 ,

20. Antrobus $S$ An analysis of nursing in context: the effects of current health policy Journal of Advanced Nursing 1997, 25:447-453

21. NHS Executive Building a Stronger Team: The Nursing Contribution to Purchasing London: Department of Health 1994,

22. Casey N A significant shortage of quailified nurses in the NHS Nursing Standard 1996, I0(17):3

23. Alderman C Here's looking at you Nursing Standard 1997, I I( I 6):23-27

24. Canavan $\mathrm{K}$ Incentive programs for nurses surfacing The American Nurse 1996 March:8

25. Salvage J A free-market tragedy Nursing Times 1996, 92(4):3

26. Hatry H, Greiner J and Ashford B Issues and Case Studies in Teacher Incentive Plans Washington: Urban Institute Press 1994,

27. Wiley $C$ What motivates employees according to over 40 years of motivation surveys International Journal of Manpower 1997, I 8(3):263-280

28. Steele L Bumpy road to success Nursing Standard 1996, I I(5):2223

29. Tumulty G, Jernigan I and Kohut G The impact of perceived work environment on job satisfaction of hospital staff nurses $A p$ plied Nursing Research 1994, 7(2):84-90

30. Stewart $M$ and Arklie $M$ Work satisfaction, stressors and support experienced by community health nurses Canadian Journal of Public Health 1994, 85(3): 180- 187

31. Smith $P$ and Agard E Care costs: Towards a critical understanding of care In Caring: The Compassion and Wisdom of Nursing. Edited by Brykcynska G. London: Arnold 1997, Chapter 9

32. Cannell M and Wood S Incentive Pay: Impact and evolution Wiltshire: The Cromwell Press 1992.

33. Thompson M and Buchan J Performance Related Pay and UK Nursing Brighton: Institute of Manpower Studies 1992,

34. Wilson B and Spence Laschinger H Staff nurse perception of job empowerment and organizational commitment Journal of Nursing Administration 1994, 24(4S):39-47
Publish with Bio Med Central and every scientist can read your work free of charge

"BioMed Central will be the most significant development for disseminating the results of biomedical research in our lifetime. "

Sir Paul Nurse, Cancer Research UK

Your research papers will be:

- available free of charge to the entire biomedical community

- peer reviewed and published immediately upon acceptance

- cited in PubMed and archived on PubMed Central

- yours - you keep the copyright
BioMedcentral 